\title{
Prolongamento da Amamentação após o Primeiro Ano de Vida: Argumentos das Mães
}

\author{
Karina Camillo Carrascoza \\ Universidade Estadual de Campinas \\ Áderson Luiz Costa Junior ${ }^{1}$ \\ Universidade de Brasília \\ Glaucia Maria Bovi Ambrosano \\ Antônio Bento Alves de Moraes \\ Universidade Estadual de Campinas
}

\begin{abstract}
RESUMO - O objetivo deste estudo foi identificar e analisar as justificativas referidas por mães para prolongar o aleitamento materno de seus filhos além do primeiro ano de vida da criança. A metodologia envolveu o estudo de 40 mães cujos filhos eram atendidos pelo Centro de Pesquisa e Atendimento Odontológico para Pacientes Especiais - Cepae - da Faculdade de Odontologia de Piracicaba - UNICAMP. Para que a mãe fosse incluída no estudo, deveria estar amamentando depois do $12^{\circ}$ mês de vida da criança. As participantes foram entrevistadas individualmente, utilizando-se um questionário específico. Todas as entrevistas foram gravadas em áudio. Os resultados mostraram que o motivo mais referido pelas mães para a manutenção da amamentação foi o prazer materno. Também foi observado que a proximidade mãe-bebê favorece o prolongamento do aleitamento. Estudos ainda são requeridos para obtenção de análises funcionais mais precisas de variáveis que levam ao prolongamento ou interrupção do aleitamento materno.
\end{abstract}

Palavras-chave: amamentação; aleitamento materno prolongado; relação mãe-bebê.

\section{Prolonged Breastfeeding: Mother's Arguments}

\begin{abstract}
This paper aims to identify and analyze the reasons pointed by mothers to prolong breastfeeding beyond the first year of the child's life. The study involved 40 mothers whose children were treated in the Preventive Program of Research and Dental Treatment Center for Special Patients - Dental School of Piracicaba - UNICAMP. The group consisted of mothers who prolonged the breastfeeding beyond the baby's first year of life. All mothers were surveyed by a researcher using a specific questionnaire. In order to avoid information loss, the interviews were taped, then transcripted. Results showed that the main cause of the extended breastfeeding was "maternal pleasure". It was also observed that the mother and infant attachment favors prolonged breastfeeding occurrence. Further studies should be carried out for more accurate functional analyses of variable that lead to extend breastfeeding or to wean.
\end{abstract}

Key words: breastfeeding; prolonged breastfeeding; mother-infant relationship.

Desde a década de 80 do século XX, observamos significativos destaques da literatura à lactação como um dos elementos essenciais ao crescimento físico, funcionamento imunológico e desenvolvimento psicológico de crianças, especialmente ao longo do primeiro ano de vida (Ichisato \& Shimo, 2002; OMS, 1994; Victora \& cols., 1987). Mais recentemente, Ramos e Almeida (2003) ressaltam que o leite humano é, consensualmente, o único alimento capaz de atender, de maneira adequada, a todas as peculiaridades fisiológicas do metabolismo dos lactentes. Além destes benefícios, os autores lembram que a prática da amamentação constitui uma condição potencial de economia para a família e para o Estado, que pode reduzir os custos com a aquisição e/ou importação de fórmulas lácteas e leite em pó para suprir as necessidades decorrentes das práticas de desmame precoce.

1 Endereço: SQN 206 Bloco G ap. 603, Brasília, DF, Brasil 70844-070. E-mail: aderson@unb.br
A divulgação de informações desta natureza, por diversos meios de comunicação científica e de senso comum, tem multiplicado os esforços jurídicos, sociais, políticos e de propaganda dirigidos ao incentivo da prática do aleitamento materno como a estratégia mais exequiível à redução da mortalidade pós-neonatal (Escuder, Venâncio \& Pereira, 2004). No entanto, enquanto uma parcela significativa de mães desmama seus filhos precocemente, utilizando-se de uma ampla variabilidade de argumentos, desde leite fraco, fome excessiva do bebê e falta de experiência (Ramos \& Almeida, 2003) até influência adversa dos avós da criança (Susin, Giugliani \& Kummer, 2005), outra parte, menos numerosa, mantém o aleitamento materno com tanto sucesso que, muitas vezes, percebe-se certo grau de dificuldade na obtenção do desmame, levando ao prolongamento da amamentação por períodos superiores a 1 ou 2 anos de vida da criança (Kummer \& cols., 2000).

Segundo Arantes (1995), em certas ocasiões, o vínculo mãe-bebê, reforçado durante a prática da amamentação, pode tornar-se tão intenso a ponto de dificultar o processo, também 
natural, de desmame. Nestes casos, o desmame pode ser encarado como uma experiência de separação, afastamento e até abandono, sendo, muitas vezes, sugerido como mais doloroso para a mãe do que para a própria criança.

Embora ainda não se observe, na literatura, uma unanimidade quanto à época ideal para a interrupção do aleitamento materno, Monte e Giugliani (2004) destacam que novos conhecimentos sobre a alimentação infantil, adquiridos nas últimas décadas, produziram mudanças significativas nas atuais recomendações alimentares de crianças amamentadas em relação às recomendações anteriores. Os alimentos complementares, por exemplo, têm sido introduzidos em uma idade mais precisa, a partir dos 6 meses de vida. Novos métodos de promoção da alimentação saudável da criança têm sido recomendados, incluindo o cuidado com o manuseio, preparo, administração e armazenamento dos alimentos e o respeito e adequação às características culturais de cada população. Neste sentido, Grummer-Strawn (1993) já chamava a atenção para divergências em relação a uma possível norma para a execução do desmame, especialmente no que se referia à variabilidade de crenças e atitudes de saúde de indivíduos expostos a diferentes contextos socioeconômicos e culturais.

Diferenças socioeconômicas sobre o processo de amamentação, abordadas por Prentice (1991), apontaram que, em países industrializados, o prolongamento do aleitamento materno tem influência reduzida sobre as condições de saúde e sobre o processo de crescimento físico das crianças. No entanto, em áreas de carência socioeconômica, especialmente de países em desenvolvimento, o prolongamento da amamentação após o primeiro ano de vida parece exercer um benefício nutricional significativo ao processo de crescimento físico e desenvolvimento das crianças.

Briend e Bari (1989), ao avaliar o impacto da amamentação sobre o estado nutricional e as condições de sobrevivência de uma amostra de 1087 crianças, com idade entre 12 e 35 meses, da zona rural de Blangladesh, mostraram um resultado aparentemente contraditório, isto é, um maior percentual de crianças desnutridas entre as que estavam em aleitamento materno do que entre aquelas que interromperam a amamentação antes do primeiro ano de vida. Entretanto, o risco de óbito era seis vezes maior entre as crianças não amamentadas do que entre as que estavam em aleitamento e apresentavam desnutrição. Embora esses dados apontem para a prevalência de uma possível condição de desnutrição materna, também são favoráveis ao incentivo do aleitamento materno além do primeiro ano de vida da criança, especialmente em comunidades com condições socioeconômicas precárias, como meio de combater os elevados índices de mortalidade infantil destas populações.

Rao e Kanade (1992) também defendem o prolongamento da amamentação em comunidades expostas a condições de carência social e econômica. Os autores estudaram os efeitos do aleitamento materno prolongado (após 1 ano de vida da criança) sobre a prevalência de desnutrição e morbidade de 395 crianças de zona rural da Índia. A amamentação demonstrou efeito benéfico e significativo sobre a redução da morbidade de crianças após o primeiro ano de vida. Para os autores, o único tipo de alimento disponível para as crianças era o leite materno e ainda existia uma situação de alto risco de contaminação biológica durante a preparação de outros alimentos, especialmente quando consideradas as inadequadas condições de higiene e de saneamento básico.

Já em populações expostas a melhores condições socioeconômicas, isto é, renda familiar equivalente a mais de cinco salários mínimos, por exemplo, a preocupação com a prevenção da mortalidade infantil é menor. Além de melhores condições ambientais de saúde, acesso à educação e saneamento básico, há maior disponibilidade para a discussão e melhor compreensão de outras questões relacionadas ao prolongamento da amamentação, como má-nutrição, recusa de alimentos sólidos e ocorrência de cáries (Rao, Hediger, Levine, Naficy \& Vik, 2002).

A associação entre duração da amamentação e estado nutricional, por exemplo, foi estudada por Victora, Vaughan, Martines e Barcelos (1984) com a participação de 802 crianças. Observou-se que a prevalência de subnutrição foi menor em crianças amamentadas entre 3 e 12 meses de idade. Porém, após esta idade, os indicadores antropométricos do estado nutricional pioravam com o prolongamento da amamentação. As crianças que ainda estavam sendo amamentadas após o primeiro ano de vida, no momento da coleta de dados, tinham uma prevalência significativamente maior de baixo peso por estatura do que aquelas que tinham sido totalmente desmamadas.

Brakohiapa e colaboradores (1988) estudaram 202 crianças em um hospital da cidade de Accra, em Ghana, observando que aquelas que estavam sendo amamentadas no peito após o primeiro ano de vida, apresentavam-se desnutridas. Os resultados mostraram que antes do desmame (interrupção completa da amamentação natural), a ingestão de nutrientes para todas as crianças desnutridas estava abaixo da metade do normal. Dez crianças realizaram o desmame e a ingestão de nutrientes foi elevada para níveis acima dos considerados normais. Já as cinco crianças que continuaram recebendo o leite materno mantiveram os níveis de nutrientes abaixo do esperado. Os autores sugerem que quando a criança está em aleitamento materno, após os 12 meses de idade e se mostra relutante em receber alimentos sólidos, o desmame deve ser efetuado.

A associação entre a amamentação e a prevalência de cáries também vem sendo estudada. Paula e Dadalto (2000), por exemplo, realizaram um levantamento epidemiológico com 311 crianças, de 0 a 3 anos de idade, residentes no município de Serra (ES), no dia da Campanha Nacional de Multivacinação. Observou-se que entre as crianças de 2 anos e meio a 3 anos, o maior índice de cárie foi encontrado naquelas que foram amamentadas por mais de 1 ano de vida, evidenciando uma potencial gravidade da doença cárie quando a amamentação é prolongada e os cuidados de higiene bucal não são adequados ou suficientes para a prevenção de transtornos bucais.

Sobre a relação entre amamentação e desenvolvimento cognitivo de crianças, Giugliani (2003) destaca que cerca de $70 \%$ dos estudos publicados sobre o tema, independente da abordagem metodológica, apontam que o aleitamento materno constitui-se em um potencial promotor do desenvolvimento cognitivo, avaliado com diferentes escores e instrumentos psicológicos.

Observa-se que, embora alguns autores, tais como Ramos e Almeida (2003), apresentem alguns argumentos utilizados 
pelas mães para justificar o prolongamento da amamentação, pouca atenção tem sido dada, pela literatura, à variabilidade dos argumentos verbalizados pelas mães e que sustentam o aleitamento natural por períodos superiores ao primeiro ano de vida da criança. Segundo Kendall (1993), as emoções e os comportamentos dos indivíduos, bem como suas justificativas, são influenciados pela percepção dos eventos ambientais disponíveis e por crenças incorporadas a partir de experiências passadas. Um conhecimento mais sistematizado dos argumentos adotados pelas mães para prolongar o aleitamento natural poderia auxiliar os pesquisadores e profissionais de saúde a adotarem estratégias mais eficientes para adesão ao aleitamento materno, desmistificação de crenças e pensamentos disfuncionais sobre a amamentação e seus efeitos, bem como fornecer indicadores comportamentais mais precisos acerca dos momentos mais adequados para promover o desmame.

O objetivo deste estudo foi descrever e analisar os motivos maternos referentes ao prolongamento do período de amamentação para além do primeiro ano de vida da criança. Para tanto, as informações obtidas junto às mães são consideradas à luz daquelas descritas pela literatura. $\mathrm{O}$ estudo também caracteriza a quantidade de mamadas e a relação com o hábito de dormir das crianças.

\section{Método}

\section{Participantes}

A amostra foi selecionada a partir de 347 mães que ingressaram no Centro de Pesquisa e Atendimento Odontológico para Pacientes Especiais (Cepae), da Faculdade de Odontologia de Piracicaba (FOP), da Universidade Estadual de Campinas (UNICAMP), no período de março de 2002 a outubro de 2003 e que tinham filhos com mais de 1 ano de idade. Das 347 mães, 43 mantinham o aleitamento materno de seus filhos além do primeiro ano de vida e 40 (representando 93\% da amostra elegível) foram selecionadas aleatoriamente. A Tabela 1 mostra a idade das crianças no momento da coleta dos dados.

Apesar de o Cepae realizar, também, o atendimento de pacientes portadores de deficiências físicas e/ou mentais, a amostra deste estudo foi constituída apenas por pacientes sadios, atestados por suas fichas de saúde, considerados especiais pelo fato de se encontrarem em uma fase do desenvolvimento que requer um ambiente de cuidados e um sistema diferenciado de atendimento às necessidades básicas de saúde.

Tabela 1. Idade da criança no momento da entrevista.

\begin{tabular}{ccc}
\hline Faixa etária (meses) & $\boldsymbol{N ( 4 0 )}$ & \% \\
\hline $12 \mid---18$ & 13 & 32,5 \\
$18 \mid---24$ & 9 & 22,5 \\
$24 \mid---30$ & 6 & 15,0 \\
$30 \mid---36$ & 8 & 20,0 \\
$\geq 36$ & 4 & 10,0 \\
\hline
\end{tabular}

\section{Contexto de realização do Estudo}

O Cepae possui uma equipe multidisciplinar composta por cirurgiões-dentistas, psicólogos, fonoaudiólogos e nutricionistas. Nesse Centro, a criança recebe cuidados preventivos de saúde bucal e geral, desde a época gestacional e até completar 5 anos de idade, por meio de visitas periódicas ao serviço. Durante esse período, a equipe disponibiliza, além de atendimento odontológico agendado e emergencial, informações nutricionais e psicológicas e treinamento fonoaudiológico para a díade mãe-criança. A filosofia de atendimento multidisciplinar tem por objetivo garantir a manutenção do aleitamento materno exclusivo até o sexto mês de vida, enfatizando a não utilização de bicos artificiais que podem precipitar o desenvolvimento de hábitos de sucção oral e suas consequiências deletérias.

\section{Instrumentos}

As informações das mães foram obtidas por meio de um questionário elaborado especificamente para este estudo. $\mathrm{O}$ questionário, constuído por 19 questões fechadas, coletava informações sobre: (a) prolongamento do aleitamento (motivos para o prolongamento e intenção de realizar o desmame); (b) variáveis socioeconômicas e demográficas (renda familiar, escolaridade e idade materna, desempenho de atividades fora do lar, estado civil, experiência prévia em aleitamento e número de filhos); (c) variáveis relacionadas ao período prénatal (recebimento de orientação sobre amamentação durante a gestação); (d) variáveis relacionadas ao período pós-natal (tipo de parto, permanência em alojamento conjunto, tempo decorrido para o início da amamentação após o parto); e (e) variáveis relacionadas à criança (permanência em creche/ escola, acompanhante da criança durante a maior parte do dia, hábito de dormir com a mãe durante a noite e freqüência de ingestão de leite materno).

\section{Procedimento}

As mães foram entrevistadas individualmente, em situação de entrevista face-a-face, em uma única sessão de, aproximadamente, 45 minutos. A entrevista foi gravada em fitas de áudio (K-7) para obtenção de maior número de dados e posteriormente transcritas "ipsis literis".

As categorias de respostas para cada um das questões integrantes do instrumento foram geradas a partir de um estudo piloto com 13 mães, expostas aos mesmos critérios de seleção das mães que participaram do estudo, que identificou as respostas mais freqüentemente verbalizadas em cada questão. No estudo propriamente dito, um único entrevistador realizou todas as entrevistas, assinalando as categorias de resposta que mais se aproximavam do relato verbal das mães. Caso não existisse uma categoria apropriada, uma nova categoria era gerada.

Após a categorização, as respostas das mães foram inseridas em planilhas do Software Microsoft Excel (versão 7.0), sendo submetidas à estatística descritiva em termos de frequiência e porcentagem. Posteriormente, os Testes Quiquadrado e Exato de Fisher foram utilizados para avaliar se havia relação estatística entre as seguintes variáveis: (a) 
vontade de interromper o aleitamento materno $\mathrm{X}$ motivo referido para o prolongamento da amamentação; (b) dormir com a mãe durante a noite $\mathrm{X}$ número de vezes que a criança é amamentada por dia; e (c) dormir com a mãe durante a noite $\mathrm{X}$ idade da mãe. Estes três cruzamentos apontaram relações estatísticas e significativas $\operatorname{com} p<0,05$.

$\mathrm{O}$ projeto de pesquisa foi submetido à apreciação do Comitê de Ética em Pesquisa da FOP/UNICAMP, tendo sido aprovado pelo protocolo $\mathrm{n}^{\circ}$ 014/2002. Todas as participantes assinaram o Termo de Consentimento Livre e Esclarecido, conforme especifica a Resolução n ${ }^{\circ}$ 196/96 do Conselho Nacional de Saúde (CNS).

\section{Resultados}

A Tabela 2 apresenta os dados sóciodemográficos e principais características das participantes deste estudo, incluindo, entre outros, idade, escolaridade, renda mensal, estado civil e experiência prévia em amamentação.

Quando as mães foram questionadas sobre os motivos da manutenção da amamentação depois do primeiro ano de vida da criança (Figura 1), $40 \%$ responderam que era por "prazer" e 30\% disseram que era pelo fato do filho "não aceitar mamadeira e/ou outro tipo de leite". Os dados também identificaram um aspecto preocupante, uma vez que $30 \%$ das mães, apesar das orientações fornecidas pela equipe multidisciplinar do Cepae, já haviam tentado introduzir a mamadeira, embora seus filhos não tivessem aceitado. Esta informação aponta que o uso da mamadeira já poderia ter se instalado há algum tempo e o desmame ocorrido.

As mães que justificaram o prolongamento da amamentação além do primeiro ano de vida pela "praticidade" (quatro

Tabela 2. Características das mães estudadas.

\begin{tabular}{|c|c|c|}
\hline Características & $N(40)$ & $\%$ \\
\hline Mães com vinte anos ou mais & 35 & 87,5 \\
\hline $\begin{array}{l}\text { Mães com mais do que o } \\
\text { primeiro grau completo }\end{array}$ & 20 & 50,0 \\
\hline $\begin{array}{l}\text { Renda familiar maior que dois } \\
\text { salários mínimos }\end{array}$ & 27 & 67,5 \\
\hline Com cônjuge residindo junto & 39 & 97,5 \\
\hline Com atividade fora fo lar & 11 & 27,5 \\
\hline Primíparas & 15 & 37,5 \\
\hline $\begin{array}{l}\text { Mães que amamentaram ao } \\
\text { menos um filho até o sexto mês } \\
\text { de vida }\end{array}$ & 18 & 45,0 \\
\hline $\begin{array}{l}\text { Mães que receberam orientação } \\
\text { sobre amamentação nesta } \\
\text { gestação }\end{array}$ & 23 & 57,5 \\
\hline Parto normal & 18 & 45,0 \\
\hline $\begin{array}{l}\text { Permanência em alojamento } \\
\text { conjunto }\end{array}$ & 16 & 40,0 \\
\hline $\begin{array}{l}\text { Início da amamentação até } \\
\text { quatro horas após o parto }\end{array}$ & 10 & 25,0 \\
\hline
\end{tabular}

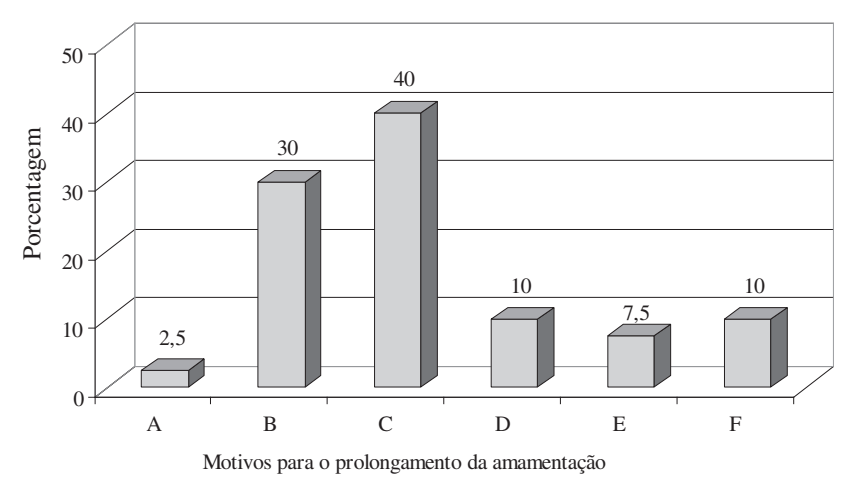

Legenda: (A) Conselho médico; (B) Não aceita mamadeira ou outro tipo de leite; (C) Prazer; (D) Praticidade; (E) Excesso de leite; (F) Dó.

Figura 1. Distribuição, em termos de porcentagem, dos motivos referidos pelas mães para o prolongamento do aleitamento materno além do primeiro ano de vida da criança.

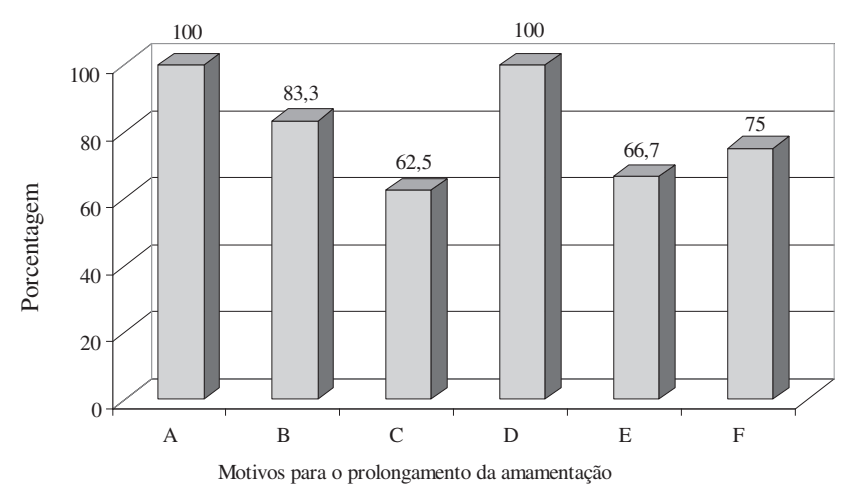

Legenda: (A) Conselho médico; (B) Não aceita mamadeira, outro tipo de leite; (C) Prazer; (D) Praticidade; (E) Excesso de leite; (F) Dó

Figura 2. Vontade de interromper a amamentação natural em função do motivo referido pelas mães para o prolongamento do aleitamento (Teste Exato de Fischer $p<0,05$ ).

mães ou $10 \%$ da amostra) relataram que, quando saíam com a criança, era mais fácil amamentá-la do que levar mamadeira, copo com válvula e/ou outros utensílios necessários para oferecer leite nos momentos em que mãe e filho estavam fora de casa, especialmente em locais públicos. Quatro mães também justificaram a manutenção do aleitamento alegando sentimentos de "dó" em relação à criança, três mães alegaram a existência de excesso de leite e uma mãe mantinha o aleitamento natural por motivo de orientação médica.

A Figura 2 mostra que, dentre as mães entrevistadas, $75 \%$ relataram que tinham vontade de parar de amamentar (30 mães), mas este dado se torna contraditório quando se observa que 16 mães (40\% da amostra) amamentaram além dos 12 meses por prazer. Esta aparente contradição pode ser analisada pelo fato de a amostra ter sido selecionada entre usuárias de um centro de pesquisa no qual as mães recebem a orientação de que deveriam iniciar o desmame somente por volta do final do primeiro ano de vida da criança, daí a alta porcentagem de mães que relatam a vontade de parar de amamentar, mas não explicitam como nem quando pretendem fazê-lo.

A única mãe que continuou a amamentar por motivo de "conselho médico" e as quatro mães que destacaram a "praticidade" da amamentação referiram vontade de inter- 


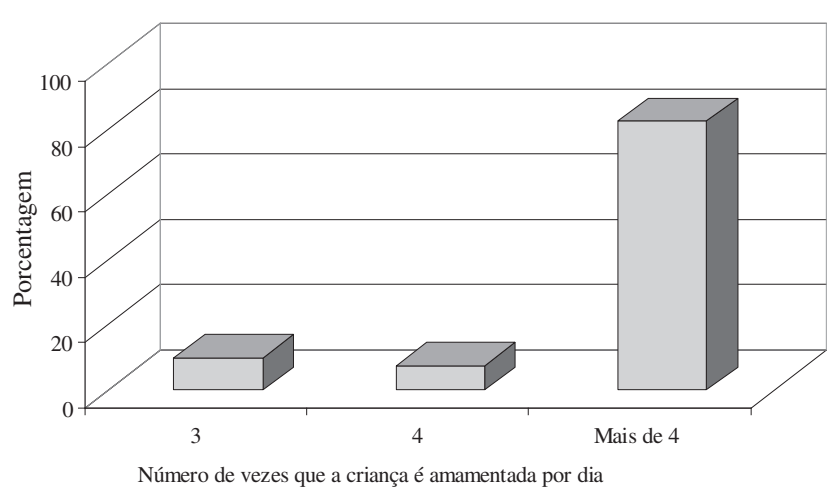

Figura 3. Distribuição, em termos de porcentagem, do número de vezes que a criança é amamentada durante o período de um dia (24 horas).

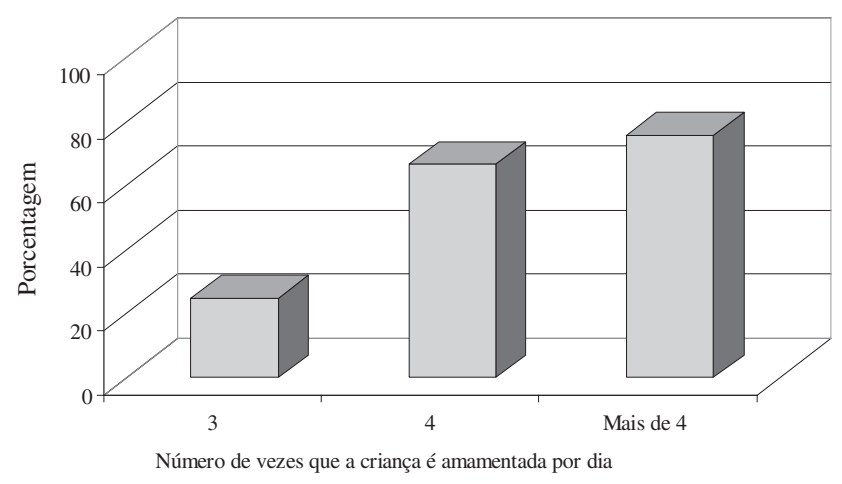

Figura 4. Crianças que dormem com suas mães em função do número de vezes que a criança é amamentada no período de um dia (Teste Exato de Fischer $p<0,05)$.

romper a amamentação. Os motivos para manter a amamentação, que apresentaram menor incidência de mães com intenção de realizar o desmame, foram "excesso de leite" $(66,7 \%)$ e "prazer" (62,5\%). Entretanto, mais da metade das mães que alegaram qualquer um dos motivos para continuar amamentando, expressaram o desejo de interromper a amamentação.

A maior parte das mães $(82,5 \%)$ relatou que seus filhos eram amamentados no peito mais de quatro vezes ao dia, incluindo o período da madrugada (Figura 3). O mesmo percentual de mães relatou que seus filhos não possuíam horários fixos para receber o leite materno, ou seja, eram amamentados no peito sempre que solicitavam.

O relato das mães permitiu apontar que $70 \%$ dos bebês (ou 28 crianças) dormiam com suas mães na mesma cama, 37 crianças (ou 92,5\% da amostra) não freqüentavam creche ou escolinha e 39 das 40 crianças passavam a maior parte do dia com a própria mãe. Os dados obtidos permitem chamar a atenção, ainda, para o fato de que dentre as crianças que faziam a ingestão de leite por mais de quatro vezes ao dia, 75,8\% delas dormiam com suas mães. Das crianças que recebiam o leite materno quatro vezes ao dia, $66,7 \%$ dormiam com a mãe. Já entre as crianças que mamavam no peito três vezes ao dia, apenas $25 \%$ dormiam com suas mães (Figura 4).

Uma possível relação entre a idade da mãe e o fato da criança dormir na mesma cama da mãe também foi investigada. Dentre as 28 crianças que dormiam com suas mães durante a noite, apenas duas eram filhas de mães com idade

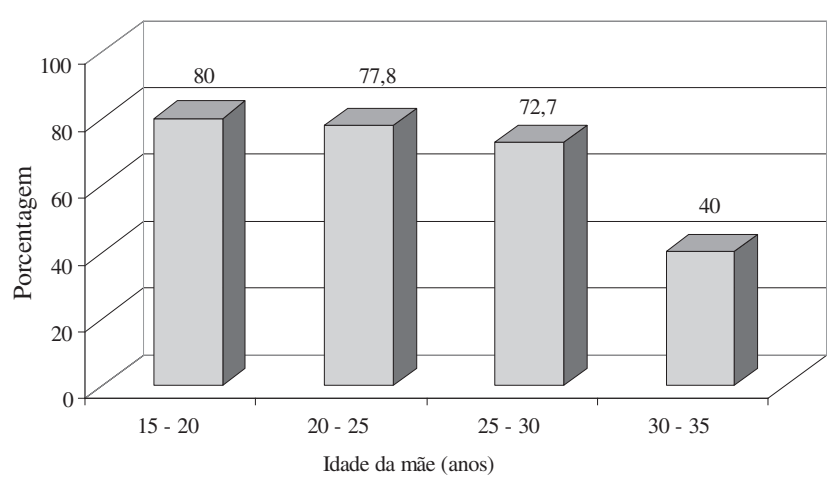

Figura 5. Crianças que dormem com suas mães durante a noite em relação à faixa etária materna (Teste Exato de Fischer $p<0,05)$.

superior a 35 anos. Pelo motivo de baixa frequiência, as faixas etárias de 35 a 40 e mais de 40 anos foram excluídas da Figura 5 , de modo a facilitar a análise da mesma.

Conforme mostrado na Figura 5, observou-se uma tendência de redução do percentual de crianças que dormiam com suas mães à medida que aumentava a idade materna, até os 35 anos, isto é, o fato da criança dormir com a mãe se mostrou inversamente proporcional ao aumento da idade da mesma.

\section{Discussão}

Ao analisar as duas respostas mais freqüentemente referidas à questão sobre os motivos da manutenção da amamentação após o primeiro ano de vida da criança, sugere-se que quando a mãe relata que continua amamentando por sentimentos de prazer, está assumindo a responsabilidade pelo prolongamento do aleitamento da criança; quando alega que o filho não aceita mamadeira e/ou outro tipo de leite, passa a responsabilidade para o filho pelo prolongamento da amamentação. É interessante apontar que as mães que apresentaram estas duas respostas tinham posições bastante diferentes em relação ao desejo de parar de amamentar, isto é, das 16 mães que referiram sentimentos de prazer para prolongar a amamentação, 10 (ou 62,5\%) não desejam, por enquanto, deixar de amamentar. Por outro lado, das 12 mães que afirmaram que seus filhos não aceitam outro leite e/ou mamadeira, apenas duas não tinham desejo de deixar de amamentar.

O prazer em manter a amamentação da criança e o desejo de não parar de amamentar sugerem valores coerentes e crenças muito íntimas, provavelmente resultado de fatores presentes no ambiente destes indivíduos, tanto doméstico quanto dos serviços de saúde utilizados. Para Kendall (1993), estas crenças constituem a base para a categorização e avaliação de experiências e estímulos que os indivíduos encontram em seus mundos.

Um dos motivos atribuídos por três mães para o prolongamento da amamentação - o excesso de leite - pareceu constituir-se em uma resposta mais conveniente, não refletin- 
do, necessariamente, o(s) motivo(s) real(is) da manutenção do aleitamento. Esta suposição pode ser justificada pelo fato da redução da produção de leite ser uma consequêencia da interrupção da amamentação, ou seja, sem o estímulo neuroendócrino proporcionado pelo ato de sucção dos mamilos, não há estímulo para a hipófise liberar prolactina e ocitocina, responsáveis pela produção do leite. Portanto, se a mãe for esperar o leite acabar para interromper a amamentação, o desmame dificilmente ocorrerá, pois o processo fisiológico é inverso, isto é, a interrupção da amamentação leva à redução da produção láctea. Além desse aspecto orgânico, levantase a hipótese de que algumas mães apresentam respostas supostamente valorizadas entre profissionais de saúde que incentivam o prolongamento do aleitamento materno, embora algumas pesquisas referidas neste estudo apontem efeitos prejudiciais do prolongamento demasiado da amamentação sob determinadas condições ambientais.

As mães que relataram sentimentos de "dó" para justificar o prolongamento da amamentação, explicaram que tinham receio de que a criança sofresse com este afastamento, encarando o desmame como um momento de separação e abandono. Nestes casos (quatro mães referiram tal argumentação), o relato de sofrimento por parte das mães sugere que o desmame, em algumas situações, poderia ser mais doloroso para a mãe do que para a própria criança, tal como descrevem Kummer e colaboradores (2000).

$\mathrm{O}$ receio, manifestado por algumas mães, de que seus filhos poderiam sofrer com o desmame pode estar associado à percepção de fragilidade freqüentemente associada aos bebês por seus cuidadores primários. Segundo Kovacs e Beck (1979), dificuldades psicológicas dessa natureza podem estar associadas a inferências incorretas elaboradas pelas mães a partir de informações inadequadas ou insuficientes. Segundo os autores, os indivíduos tendem a formular regras rígidas baseadas em suposições nem sempre verdadeiras. Baseado nesta hipótese, programas de preparação de gestantes que disponibilizem informações básicas, por exemplo, sobre cuidados com o bebê e sobre o processo de desenvolvimento infantil, poderiam reduzir a probabilidade da formação de crenças inadequadas.

Considerando que apenas uma mãe referiu a "orientação médica" como motivo para o prolongamento da amamentação além do primeiro ano de vida da criança e como a coleta de dados deste estudo se baseou, exclusivamente, em relatos verbais de mães, não se pode afirmar, com certeza, que o médico realmente tenha efetuado tal orientação, ou que a mãe a utilizou para que não fosse questionada sobre sua decisão. Ressalta-se que o médico ainda representa, de modo geral, uma figura de autoridade e conhecimento quase inquestionável dentro da sociedade, especialmente frente a usuários de sistemas de saúde pública e de classes socioeconômicas menos privilegiadas.

A informação de que $82,5 \%$ das mães relataram que seus filhos eram amamentados no peito mais de quatro vezes ao dia, incluindo o período da madrugada, acarreta duas implicações relevantes ao estudo: (a) confirma o enfrentamento de dificuldades, por parte das mães, em restringir a frequiência das mamadas, mesmo depois do primeiro ano de vida da criança; e (b) aponta que esta prática está em desacordo com grande parte da literatura, que a partir do sétimo mês após o parto incentiva as mães a amamentar seus filhos, no peito, apenas três vezes ao dia e nenhuma vez durante a madrugada (Ramos \& Stein, 2000).

A alta frequiência de relato de amamentações por dia sugere que tal informação esteja relacionada ao prazer que as mães sentem em amamentar, impedindo-as de impor limites para a ocorrência da amamentação. Da mesma forma, estes dados confirmam os resultados de Dini, Holt e Bedi (2000), que encontraram alta freqüência de ingestão de leite materno em crianças com aleitamento materno prolongado.

A baixa freqüência de bebês que freqüentavam creche e a alta frequiência de bebês que dormiam com suas mães, na mesma cama, sugere que a proximidade entre mãe e filho poderia favorecer a ocorrência do aleitamento materno prolongado. O trabalho de Weerheijm, Uyttendaele-Speybrouck, Euwe e Groen (1998), por exemplo, demonstrou que 60\% das crianças que receberam aleitamento materno além do primeiro ano de vida dormiam com suas mães durante a noite, permitindo acesso fácil e direto ao leite materno.

Conforme os dados obtidos, seis mães relataram que o fato de manter a criança em aleitamento materno além do primeiro ano de vida era uma forma de garantir o afastamento do marido, evitando, assim, contatos íntimos e de cunho sexual. No caso destas seis mães, quatro tinham crianças entre 2 anos e meio e 3 anos de idade e duas mães tinham crianças com mais de 3 anos, isto mostra que esta prática aumentava, de fato, a probabilidade de prolongamento do aleitamento materno.

Por outro lado, o fato de a criança dormir com a mãe durante a noite sugere a existência de problemas conjugais, ou uma aparente separação entre a dupla função - amamentação e erotismo - dos seios femininos, tal como descreve Sandre-Pereira (2003). Segundo esta autora, "as representações que homem e mulher fazem da maternidade aparecem como a base de alterações importantes na sexualidade do casal durante o período de aleitamento materno" (p. 467). Ressalta-se que algumas mães deste estudo relataram que o companheiro dormia em outra cama, ou até mesmo em outro cômodo da casa, durante todo o período de manutenção da amamentação da criança (o que implicaria em períodos superiores a dois ou até três anos de separação).

\section{Considerações Finais}

Embora os argumentos referidos pelas mães deste estudo tenham sido, em sua maior parte, coerentes com os referidos pela literatura, as pesquisas que investigam os diversos temas relacionados ao aleitamento materno, sua interrupção precoce ou prolongamento, ainda requerem uma maior compreensão da variabilidade de argumentações e suas relações funcionais com crenças, atitudes e estratégias de enfrentamento adotadas por mães e demais familiares.

Segundo Kendall (1993), valores e crenças disfuncionais são construídos ao longo da história dos indivíduos e mantidos especialmente em ambiente que não disponibilizam informações ou estímulos que possam confrontar tais crenças. Neste sentido, os serviços de saúde poderiam priorizar o delineamento de investigações que permitissem identificar e analisar o repertório comportamental e cognitivo de seus usuários, de modo a dispor de intervenções mais eficientes 
e pontualmente relacionadas às vulnerabilidades das mães, que as motivam a interromper e/ou prolongar a amamentação de seus filhos(as).

Estudos multicêntricos e com amostras ampliadas devem constituir um dos objetivos das pesquisas que analisam os argumentos adotados pelas mães para justificar o prolongamento do aleitamento materno por períodos superiores a um ano de vida de seus filhos.

\section{Referências}

Arantes, C. I. S. (1995). Amamentação - visão das mulheres que amamentam. Journal of Pediatrics, 71(4), 195-202.

Brakohiapa, L. A., Bille, A., Quansah, E., Kishi, K., Yartey, J. \& Harrison, E. (1988). Does prolonged breastfeeding adversely affect a child's nutritional status? The Lancet North American, 20(3), 416-418.

Briend, A. \& Bari, A. (1989). Breastfeeding improves survival, but not nutritional status, of 12-35 months old children in rural Bangladesh. European Journal of Clinical Nutition, 43(5), 603-608.

Dini, E. L., Holt, R. D. \& Bedi, R. (2000). Caries and its association with infant feeding and oral health - related behaviors in 3-4 year-old brazilian children. Community Denistry and Oral Epidemiology, 28(4), 241-248.

Escuder, M. M. L., Venâncio, S. I. \& Pereira, J. C. R. (2004). Expectativa de impacto da amamentação sobre a mortalidade infantil. Revista de Saúde Pública, 37(3), 319-325.

Giugliani, E. (2003). Aleitamento materno e desenvolvimento cognitivo. Jornal de Pediatria, 79(1), 98-99.

Grummer-Strawn, L. M. (1993). Does prolonged breast-feeding impair child growth? A critical review. Pediatrics, 91(4), 766-771.

Ichisato, S. M. T. \& Shimo, A. K. K. (2002). Revisitando o desmame precoce através de recortes da história. Revista Latinoamericana de Enfermagem, 10(4), 578-585.

Kendall, P.C. (1993). Cognitiva-behavioral therapies with Youth: Guiding theory, current status, and emerging developments. Journal of Consulting and Clinical Psychology, 61(3), 235247.

Kovacs, M. \& Beck, A. T. (1979). Cognitive-affective processes in depression. Em C. E. Izard (Org.), Emotions in personality and psychophatology (pp. 417-442). N. York: Plenum Press.

Kummer, S. C., Giugliani, E. R. J., Susin, L. O., Folletto, J.L., Lermen, N. R. \& Wu, V. Y. J. (2000). Evolução do padrão de aleitamento materno. Revista de Saúde Pública, 34(2), 143-148.

Monte, C. M. G. \& Giugliani, E. R. J. (2004). Recomendações para alimentação complementar da criança em aleitamento materno. Jornal de Pediatria, 80(5), 131-141.
Organização Mundial da Saúde (1994). Lactação. Em Organização Mundial da Saúde (Org.), Alimentação infantil: bases fisiológicas (pp. 39-48). São Paulo: IBFAN/OMS/OPAS/UNICEF.

Paula, M. P. G. \& Dadalto, E. C. V. (2000). Prevalência de cárie em crianças de 0 a 36 meses de idade. Revista da Associação Brasileira de Odontologia - Nacional, 8 (2), 86-91.

Prentice, A. (1991). Breast feeding and the older infant. Acta Paediatrica Scandinavica, 374(1), 78-88.

Ramos, C. V. \& Almeida, J. A. G. (2003). Alegações maternas para o desmame: estudo qualitativo. Jornal de Pediatria, 79(5), 385-390.

Ramos, M. \& Stein, L. M. (2000). Desenvolvimento do comportamento alimentar infantil. Journal of Pediatrics, 76 (Suppl 3), 229-237.

Rao, M. R., Hediger, M. L., Levine, R. J., Naficy, A. B. \& Vik, T. (2002). Effect of breastfeeding on cognitive development of infants born small for gestational age. Acta Paediatrica, 91(2), 267-274.

Rao, S. \& Kanade, A. N. (1992). Prolonged breastfeeding and malnutrition among rural indian children below 3 years of age. European Journal of Clinical Nutrition, 46(2), 187-197.

Sandre-Pereira, G. (2003). Amamentação e sexualidade. Estudos Feministas, 11(3), 467-491.

Susin, L. R. O., Giugliani, E. R. J. \& Kummer, S. C. (2005). Influência das avós na prática do aleitamento Materno. Revista de Saúde Pública, 39(2), 141-147.

Victora, C. G., Smith, P. G., Vaugham, J. P., Nobre, L. C., Teixeira, A. M. B., Fuchs, S. M. C., Moreira, L. B., Gigante, L. P. \& Barros, F.C. (1987). Evidence for protection by breast-feeding against infants deaths from infectious diseases in Brazil. Lancet, 2(3), 319-321.

Victora, C. G., Vaughan, J. P., Martines, J. C. \& Barcelos, L. B. (1984). Is prolonged breast-feeding associated with malnutrition? American Journal of Clinical Nutrition, 39(4), 307-314.

Weerheijm, K. L., Uyttendaele-Speybrouck, B. F. M., Euwe, H. C. \& Groen, H. J. (1998). Prolonged demand breast-feeding and nursing caries. Caries Research, 32(1), 46-50.

Recebido em 26.09.2005

Primeira decisão editorial em 24.11.2005

Versão final em 24.11.2005

Aceito em 29.11.2005 